\title{
Detection of Respiratory Syncytial Virus and Human Metapneumovirus in Children with Respiratory Tract Infection by Use Real Time Polymerase Chain Reaction Hala Luay Abduljabbar(Bsc $)^{1}$, Areej Atiyah Hussein( $(\mathrm{PhD})^{2}$, Iman M Aufi(MSc) ${ }^{3}$ and Qasim Sharhan Al-Mayah $(\mathrm{PhD})^{4}$
}

\begin{abstract}
Background: Respiratory tract illness is a major cause of morbidity and mortality among children, elderly and immunocompromised patients worldwide.

Objective: To determine the infection rate of respiratory syncytial virus and human metapneumovirus among children with respiratory tract infection in Baghdad city.

Patients and Methods: A cross sectional study was based on the processing of nasopharyngeal swabs from 150 children with acute respiratory tract infections, (81) males and (69)females; aged under five years old, who was admitted to Al-Imamin Al-Kadhimin Medical City and Pediatrics Protection Hospital in Baghdad during the period from December 2017 till April 2018. Nasopharyngeal swabs were collected from each participant and stored as frozen at $-70{ }^{\circ} \mathrm{C}$ to use for RNA extraction and real time- polymerase chain reaction.
\end{abstract}

Results: Out of all these samples, 54 samples were positive for respiratory syncytial virus (36\%) and human metapneumovirus $(1.33 \%)$. The infection rate of respiratory syncytial virus is more common in males $(57.41 \%)$ than females and in children $\leq$ one year $(37.04 \%)$ also high frequency were noticed among patients live in an urban area (72.22\%) (50\%) respectively and winter. According to different clinical feature, fever, cough, and wheezing were more common. Conclusion: The infection rate of respiratory syncytial virus was more than human metapneumovirus in children with respiratory tract infection using real time-PCR technique and the clinical manifestations were more common during respiratory syncytial virus and human metapneumovirus infection are cough, fever, wheezing.

Key words: Respiratory tract infection, respiratory syncytial virus, human metapneumovirus, real time-PCR.

Corresponding Author: areej.2002@yahoo.com

Received: $31^{\text {th }}$ October 2018

Accepted: $21^{\text {th }}$ November 2018

https://doi.org/10.26505/DJM

${ }^{1,2}$ Department of Microbiology - College of Medicine - University of Diyala - Iraq.

${ }^{3}$ National Influenza Center - Central Public Health Laboratory - Iraq .

${ }^{4}$ Medical Research Unit - College of Medicine - Al-Nahrain University - Iraq.

\section{Introduction}

Acute respiratory infection (ARI) is the major cause of morbidity and mortality. In young children, the elderly, and immunocompromised individuals throughout the world [1]. Several types of viral families such as

Orthomyxoviridae, Adenoviridae, and Coronaviridae which considered the major viral etiological agents of ARI in all age groups [2]. 
Detection of Respiratory Syncytial Virus and Human Metapneumovirus in Children with Respiratory

Tract Infection by Use Real Time Polymerase Chain Reaction

Respiratory syncytial virus (RSV) and human metapneumovirus (hMPV) component of a single strand, negative sense RNA genome, helical nucleocapsid, and they are enveloped [3]. Rspiratory syncytial infection and hMPV are believed to transmit through close contact with a person who has an active infection or direct contact with infectious secretions on environmental surfaces such as droplets, saliva, or large particle aerosols [4]. Despite the fact that fomites may be a source of contamination [5].

The human metapneumo virus is closely associated with respiratory syncytial virus, by far the most essential airway virus influencing children worldwide [6]. It has been accounted that the RSV and hMPV infections in children may be quite similar [7]. But there is also some confirmation that RSV causes more serious ailment than HMPV. Risk factors for extreme RSV infection are young age, prematurity, chronic lung illness, chronic heart illness and serious neurological disabilities [8].

Respiratory syncytial virus and hMPV infection are blurred distinguishable, both they cause upper respiratory infection which begins with flu-like illness, fever; headache; sneezing, and then progresses down into the lower respiratory tract to cause bronchiolitis, pneumonia, and they implicated with allergy and asthma exacerbation [9]. Respiratory syncytial virus constitutes more than $60 \%$ of respiratory tract infection, while human metapneumovirus around 12\% [10]. Re infection in RSV and hMPV happens with comparable strains in spite of normal infection stimulating high levels of antibody against conserved antigens [11].

The diagnosis of RSV and hMPV infections can be made by several techniques, including culture, nucleic acid amplification tests (NAAT), antigen detection and serology test, but detection of viral RNA by NAAT such as reverse transcriptase-PCR (RT-PCR) assay is the most sensitive method for diagnosis of RSV and hMPV infections [12].

In Iraq, several studies have been conducted in various provinces to identify these viruses such as study done by Al-Mola et al (2013) in Hilla city[13], Aziz (2015) in Sulaimani city[14], Al-Ameedy (2016) in Najaf city[15], Al-Charrakh et al (2016) in Wasit province[16], Al-Mossawi et al (2016) in Al-Amarah City[17] and finally Atyah et al (2017) in Baghdad city[18]. This study design to investigate of co infection between RSV and hMPV in children under five year's age.

\section{Patients and Methods}

\section{Study population and selection of patients}

A cross sectional study was based on the processing of nasopharyngeal from one hundred fifty (69 females and 81 males) under five years old who was admitted to AlImamin Al-Kadhimin Medical City and Pediatrics Protection Hospital in Baghdad during the period from December 2017 till April 2018. Data were collected by interview with each parent of a participant or relevant through structural questionnaire which include age, gender, season, residence, fever, cough, wheezing, history of 
Detection of Respiratory Syncytial Virus and Human Metapneumovirus in Children with Respiratory

Tract Infection by Use Real Time Polymerase Chain Reaction

asthma, nasal discharge, type of infection and diarrhea.

Nasopharyngeal swab received in viral transport media (Sigma Virocult Company, UK) without antibiotics [19]. And transportation of swabs by a cool box to the virology unit at the National Central Public Health Laboratory. Then were vortexed for 15 seconds to dislodge material on the swab into the transport medium. On completion of routine investigations for microbial causes of respiratory tract infection all residual nasopharyngeal aspirate samples were divided into aliquots, labelled and stored at $2^{\circ} \mathrm{C}$ to $8^{\circ} \mathrm{C}$ for no longer than 24 hours or frozen at $-70^{\circ} \mathrm{C}$ for prolonged storage until the time of analysis.

\section{RSV and hMPV detection}

Viral RNA was extracted from nasopharyngeal swab using RNA extraction kit quick protocol kit (Cat. No.52906 Qiagen - Germany), according to the manufacturer's instructions In this study, we used a real-time RT-PCR assay for the detection of RSV and hMPV in a 7500 fast Applied Bio- systems instrument.

For the RSV F gene detection, the amplification done by using forward primer sequence (5-GGC AAA TAT GGA AAC ATA CGT GAA-3), with reverse primer (5-TCT TTTTCT AGG ACA TTG TAY TGA ACA G-3) and probe (5-CTG TGT ATG TGG AGC CTT CGT GAA GCT-3). The probe was labeled with $5^{\prime}$ reporter dye FAM and the 3'at a nonfluorescent dye BHQ1 [20].
While one pair of specific primers are tested to reverse transcribe and amplify the human metapneumovirus highly conserved $\mathrm{F}$ genes. Primers were highly specific for the $\mathrm{F}$ capsid genes of the HMPV, the forward sequence primer was (5'- CAA GTG TGA CAT TGC TGA YCT RAA -'3), reverse primer (5'-

ACTGCCGCACAACAACATTTAGRAA'3) and Probe (5'TGGCYGTYAGCTTCAGTCAATTCAAC AGA -'3). The probe for hMPV uses FAM dye on the 5' reporter end and a nonfluorescent dye on the 3 ' quencher end [21].

The master mix in use for the one step RTPCR of RSV and Hmpv detection was Ag path-ID ${ }^{\mathrm{TM}}$ one step RT-PCR kit (P/N AM1005,437424 and 4387391, Applied Biosystem, USA). were added to $12.5 \mu 1$ of $2 \mathrm{x}$ RT-PCR buffer, $1 \mu 1$ of $25 x$ RT-PCR enzyme Mix, $0.5 \mu 1$ pmol conc. of each primer and $0.5 \mu \mathrm{l}$ pmol conc of the probe, $5 \mu \mathrm{l}$ of Nuclease free-water, $5 \mu 1$ of RNA templates, the total of reaction mixture $25 \mu$ l. Amplification and detection were done with an Applied Biosystem7500. Briefly, one cycle for $1 \mathrm{~min}$ at $45 \mathrm{C}^{\circ}$ and $10 \mathrm{~min}$ at $95 \mathrm{C}^{\circ}$, followed by 45 cycles for $15 \mathrm{~s}$ at $95 \mathrm{C}^{\circ}$ and 1 $\min$ at $55 \mathrm{C}^{\circ}$.

\section{Results}

The rate of respiratory syncytial virus infection among children under five years age was 36\% (54 out of 150) samples and human metapneumovirus was $1.33 \%$ (2 out 
of 150) samples by Real time PCR as shown in Table (1) and Figures (1), (2).

Table (1): Infection rate of RSV and hMPV in children with respiratory tract infection by real time PCR.

\begin{tabular}{||l|c||c|}
\hline \multicolumn{1}{|c|}{ Viruses } & Examined No. & Positivity (\%) \\
\hline \hline Respiratory syncytial virus & 150 & $54(36 \%)$ \\
\hline \hline Human metapneumo virus & 150 & $2(1.33 \%)$ \\
\hline
\end{tabular}

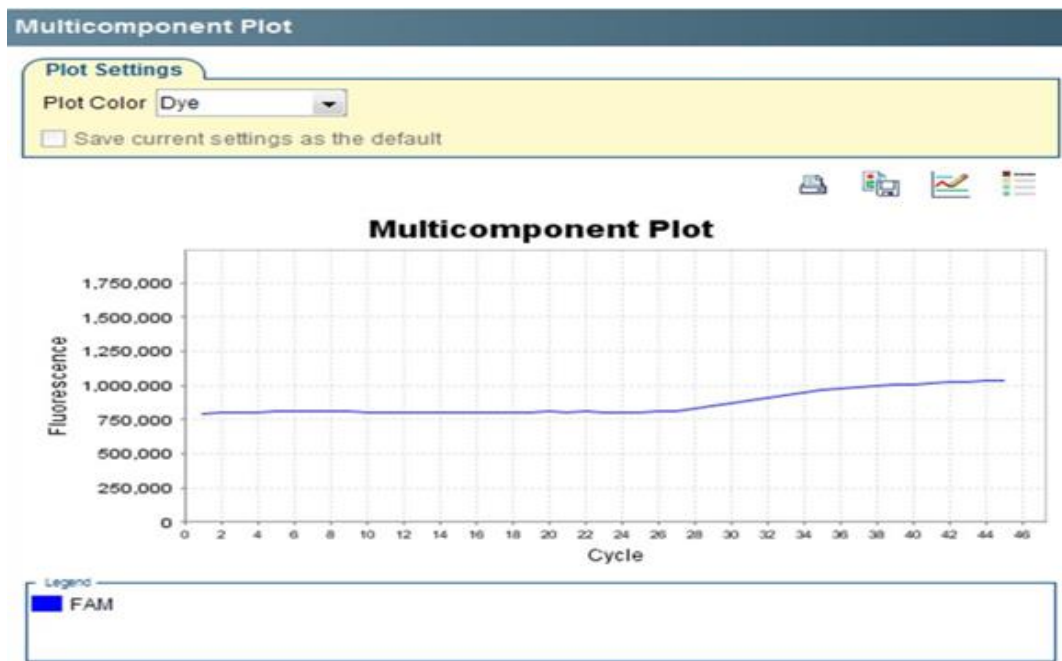

Figure (1): Real time PCR of human respiratory syncytial virus.

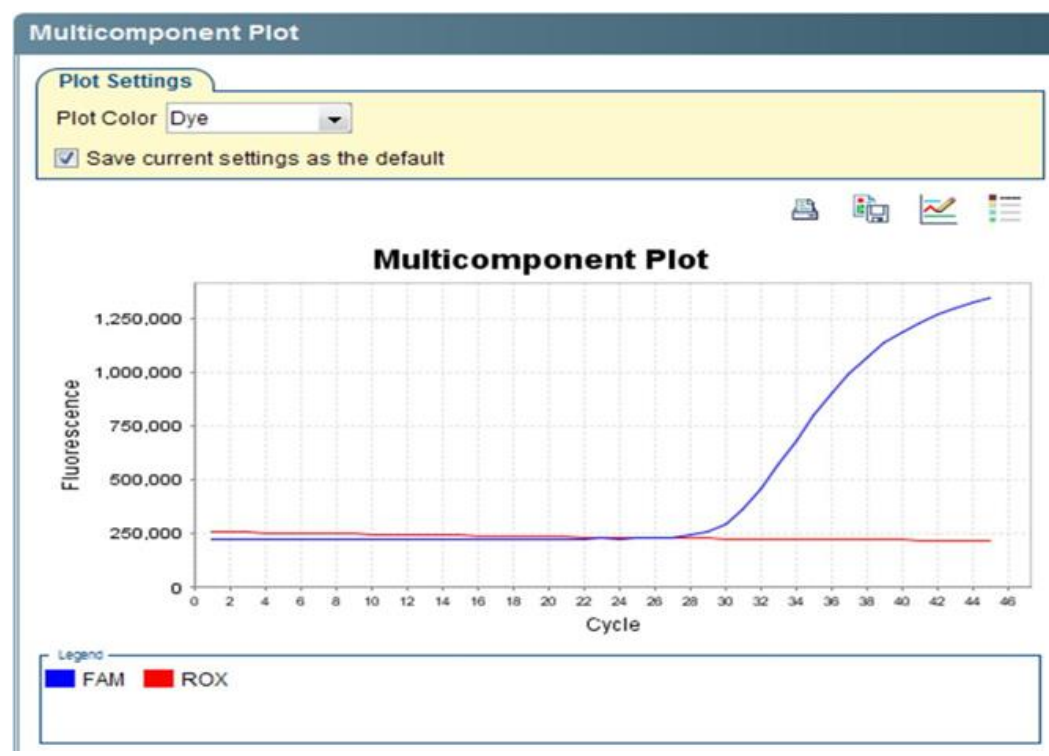

Figure (2): Real time PCR of human metapneumovirus.

Infection with respiratory syncytial virus infection rates $(37.04 \%)$ were noticed in was more common in males $31(57.41 \%)$ age group

(1-12 month) than females 23 (42.59\%). The highest followed by (13-24 months). Most 
Detection of Respiratory Syncytial Virus and Human Metapneumovirus in Children with Respiratory

Tract Infection by Use Real Time Polymerase Chain Reaction

infections occurred in urban area $72.22 \%$. While human metapneumo virus infection had equally percentage regarding gender and residence as well as equal present $50 \%$ in the age group 1-12 month, and 13-24 month, also a high percentage of infection were recorded in urban area as shown in the Table (2).

Table (2): Distribution of RSV and hMPV in patients with RTI according to demographic features using real time - PCR.

\begin{tabular}{|c|c|c|c|}
\hline \multicolumn{2}{|c|}{ Variable factors } & \multirow{2}{*}{$\begin{array}{c}\text { RSV } \\
\text { No. Samples (\%) } \\
31(57.41 \%)\end{array}$} & \multirow{2}{*}{$\begin{array}{c}\text { HMPV } \\
\text { No. Samples (\%) } \\
1(50 \%)\end{array}$} \\
\hline Gender type & Male & & \\
\hline & Female & $23(42.59 \%)$ & $1(50 \%)$ \\
\hline \multirow[t]{5}{*}{ Age groups } & (1-12) months & $20(37.04 \%)$ & $1(50 \%)$ \\
\hline & (13-24) months & $15(27.78 \%)$ & $1(50 \%)$ \\
\hline & (25-36) months & $10(18.52 \%)$ & \\
\hline & (37-48) months & $5(9.26 \%)$ & \\
\hline & (49-60) months & $4(7.41 \%)$ & \\
\hline \multirow[t]{2}{*}{ Residence } & Rural & $15(27.78 \%)$ & $1(50 \%)$ \\
\hline & Urban & $39(72.22 \%)$ & $1(50 \%)$ \\
\hline \multirow{2}{*}{ Seasons } & Winter & $42(77.78 \%)$ & 1 \\
\hline & Spring & $12(22.22 \%)$ & $1(50 \%)$ \\
\hline
\end{tabular}

Distribution of RSV infection, according to the clinical features were detailed in Table (3), $\quad 35$ (64.81\%) children were suffering from lower respiratory tract infection, 53(98.15\%) had a cough while 49(90.74\%) had fever, 43(79.63\%) were suffering from wheezing, $27.78 \%$ of children had a history of asthma. Nasal discharge are present in $68.58 \%$ and $42.59 \%$ were suffering from diarrhea. On the other hand relation between human metapneumo virus infection and clinical features showed that all children had a lower respiratory tract infection, cough, fever and wheezing while $50 \%$ of children had a history of asthma, nasal discharge and diarrhea. 
Detection of Respiratory Syncytial Virus and Human Metapneumovirus in Children with Respiratory

Tract Infection by Use Real Time Polymerase Chain Reaction

Table (3): Distribution of RSV and hMPV in patients with RTI according to clinical features using real time PCR.

\begin{tabular}{|c|c|c|c||}
\hline \multicolumn{2}{|c|}{ Variable factors } & $\begin{array}{c}\text { RSV } \\
\text { No. Samples (\%) }\end{array}$ & $\begin{array}{c}\text { hMPV } \\
\text { No. Samples (\%) }\end{array}$ \\
\hline \multirow{3}{*}{ RTI } & Upper & $19(35.19 \%)$ & 0 \\
\cline { 2 - 4 } & Lowe & $35(64.81 \%)$ & $2(100 \%)$ \\
\hline \multirow{3}{*}{ Cough } & Yes & $53(98.15 \%)$ & $2(100 \%)$ \\
\cline { 2 - 4 } & Lower & $1(1.85 \%)$ & \\
\hline \hline \multirow{3}{*}{ Fever } & Yes & $49(90.74 \%)$ & $2(100 \%)$ \\
\hline \hline \multirow{2}{*}{ History of asthma } & No & $5(9.26 \%)$ & \\
\cline { 2 - 5 } & Yes & $43(79.63 \%)$ & $2(100 \%)$ \\
\hline \hline \multirow{2}{*}{ Nasal discharge } & No & $11(20.37 \%)$ & 0 \\
\cline { 2 - 5 } & Yes & $15(27.78 \%)$ & $1(50 \%)$ \\
\hline \hline \multirow{2}{*}{ Diarrhea } & Yes & $39(72.22 \%)$ & $1(50 \%)$ \\
\cline { 2 - 5 } & No & $17(31.49 \%)$ & $1(50 \%)$ \\
\hline & Yes & $23(42.59 \%)$ & $1(50 \%)$ \\
\hline
\end{tabular}

\section{Discussion}

The infection rate of the current study was $36 \%$ of RSV infections and $1.33 \%$ of hMPV infections by real time polymerase chain reaction The infection rate of RSV use real time-PCR is comparable with several studies conducted in different area such as Khadadah et al. (2010) reports that the percentage of infections is $36.8 \%$ in hospitalized children with respiratory tract infection in Kuwait[22] and with a study done by Parsania et al., (2016) shows that $31.1 \%$ of RSV infections among Iranian children $<5$ years of age [23].

The infection rate of RSV in this study is relatively low compared with data reported in Baghdad by Odisho et al. (2009), the percentage is reached to $79 \%$ among the children who have a respiratory tract infection [24]. In this study the infection rate seems to be lower with than other studies such as study done by Atyah et al., 2017 who recorded $(6.6 \%)$ in children under 15 years old in Baghdad [18]. Another study done by Al-Charrakh et al., (2016) recorded (18.75\%) in asthmatic patients used real time polymerase chain reaction in Wasit city [16]. The positive rate of hMPV in the current study was (1.33\%) comparable to results was obtained by Zhang et al., (2018) detected in $2 \%$ (103 out of 5133) of ARI 
Detection of Respiratory Syncytial Virus and Human Metapneumovirus in Children with Respiratory

Tract Infection by Use Real Time Polymerase Chain Reaction

patients in Southern China [25]. Also, this result consistent with that reported by Mohamed et al.,(2014) showed 4\% in Egypt [26] and Essa et al., (2015) found 5.3\% in Kuwait [27]. Other studies found different percentages ranging from $(1.5 \%-18.2 \%)$ [28][29][30]. These differences in frequency in the reports might reveal changed epidemiological outlines of RSV and hMPV infections in various countries, which in turn might be linked to environmental features, geographical factors, differences in host genetic predisposition, immune status, size of the sample, method for detection, and different viral strains going into various geographical zones [31]. According to gender, it has been found that RSV infection in males more than females seems to be similar to those who participated in other studies such as, Zahran et al., (2017) in Egypt [12] and Hassan et al., (2018) in Iraq [32]. While the current study is inconsistent with a study conducted by Reina et al., (2008) which revealed that the gender, females $(53.2 \%)$ was higher than males among children infected with hMPV[33]. And with Zuo, et al., (2009) found no significant differences regarding sex in children positive to hMPV[34]. Regarding the age, it shows that infections with RSV were more common in age group $<1$ year, 20(37.04\%) use a real time PCR technique, when compared to older children. This result was comparable to that Chen et al.,(2010) in china [35] and Khalil et al., (2015) in Egypt [36], The incidence of severe RSV infections was highest among infants and young toddlers and peaked in the 1 to 2 month-old infants.

Data obtained from this study indicate that most positive patients of RSV from urban area and exactly $39(72.22 \%$ ), (Table 2 ), this result which agreed to similar study that has reported increased infections in Kurdistan region of Iraq [32]. In contrast, this result disagreed with a study done by Aziz (2015) to detect hMPV [14]. The reason of high prevalence in the urban residence could be related to crowded and bad hygiene in the large cities.

In the current study, seasonal peaks of the RSV and hMPV were circulated primarily during the winter and early spring in Iraq, this result in agreement with Al-Shami et al., (2009) who mentioned that ratio was higher in January and February in Iraq [37]. And with another study done by Banerjee et al., (2011) hMPV circulated predominantly during the winter-spring period of 2010-2011 [38].Different type of clinical feature was studied in this study, It has been shown that LRTI may be associated with higher RSV and hMPV viral loads than URTI that is agreement study done by Bosis et al., (2008) [39] and Zhang et al., (2018) [25].

Fever is generally more widespread among children with respiratory tract infection, this result in agreement with previous study done by Aziz et al., (2015) reported fever and wheezing were more common clinical sign in children with hMPV [14].While Ji Wang, et al., (2009) found fever, cough, and rhinorrhea were more common than other signs. This might reveal the wide-ranging 
Detection of Respiratory Syncytial Virus and Human Metapneumovirus in Children with Respiratory

Tract Infection by Use Real Time Polymerase Chain Reaction

signs during viral infection [40]. The most frequent symptoms of hMPV are fever and cough, in accordance with a study done by Zhou et al., (2017) among hMPV positive cases fever was 33(82.50\%) [30]. And Zeng et al., (2015) [6]. Concerning the cough and wheezing, Ali et al., (2010) in reported the clinical signs associated with hMPV infection were similar to those of other respiratory viruses, except children with hMPV were more likely to present with fever than children not infected with hMPV, also Cough 100\% and Wheezing 89\% [41]. Zahran et al., (2017) found wheezing $(85.7 \%)$, cough $(66.7 \%)$, and fever $(70 \%)$ [12].The results of the present study showed $(27.78 \%)$ of RSV and $(50 \%)$ of hMPV infection may be associated with asthma exacerbation which are in agreement study done by Da silva et al (2013) [42] and with Wu et al., (2008) who mentioned at winter, the virus peak had an increased risk of bronchiolitis in infancy and of asthma during childhood in USA [43].Concerning diarrhea, this study showed that 23 cases $(42.59 \%)$ RSV-positive children were suffering from diarrhea. which is in agreement with previous reports done by Hassan et al., (2018) reported 13 out of 20 (6.4\%) cases had diarrhea in hospitalized children from the Kurdistan region [32] other study found that diarrhoea was more common in patients with hMPV plus other pathogens detected $(22.2 \%, 4 / 18)$, compared with patients with hMPV only $(3.6 \%, 3 / 83)$ (Zhang et al., 2018) [25].

\section{Conclusions}

The infection rate of respiratory syncytial virus was more than human metapneumovirus in children with respiratory tract infection using real timePCR technique and the clinical manifestations were more common during respiratory syncytial virus and human metapneumovirus infection are cough, fever, wheezing. Further study with large sample size are needed to clarify this issue as well as study role of other viruses in co-infection.

\section{References}

[1]Zhang HY, Li ZM, Zhang GL, Diao TT, Cao CX, Sun HQ. Respiratory viruses in hospitalized children with acute lower respiratory tract infections in harbin. China. Jpn J Infect Dis. 2009; 62(6):458-60. t. Quim Nova. 2009;7(32):1764-1769.

[2]Bertino JS. Cost burden of viral respiratory infections: issues for formulary decision makers. Am J Med. 2002; 112:42S49S.

[3] Nagakumar P, Doull I. Current therapy for bronchiolitis. Arch Dis Child. 2012; 97(9): 827-830.

[4]Haas LE, Thijsen SF, van Elden L, Heemstra KA. Human metapneumovirus in adults. Viruses. 2013; 5(1): 87-110.

[5]Tollefson SJ, Cox RG, Williams JV. Studies of culture conditions and environmentalstability of human metapneumovirus. Virus Res. 2010; 151(1): 54-59.

[6]Zeng SZ, Xiao NG, Zhong LL, Yu T, Zhang B, Duan ZJ. Clinical features of human metapneumovirus genotypes in 
Detection of Respiratory Syncytial Virus and Human Metapneumovirus in Children with Respiratory

Tract Infection by Use Real Time Polymerase Chain Reaction

children with acute lower respiratory tract infection in Changsha, China. J Med Virol. 2015; 87:1839-1845.

[7]Adams O, Weis J, Jasinska K, Vogel M, Tenenbaum T. Bertino Rhinovirus respiratory tract infections in young children admitted to hospital. J Med Virol. 2015; 87: 275-280.

[8]De Waal L, Smits SL, Veldhuis Kroeze EJ, Van Amerongen G, Pohl MO, Osterhaus $\mathrm{AD}$, et al., Transmission of human respiratory syncytial virus in the immunocompromised ferret model. Viruses. 2018; 10(1):18.

[9] Rezaee F, Linfield DT, Harford TJ, Piedimonte G. Ongoing developments in RSV prophylaxis: A clinician's analysis. Curr Opin Virol. 2017; 24:70-78.

[10]Kahn JS. Epidemiology of human metapneumovirus. Clin Microbiol Rev. 2006; 19(3): 546-557.

[11]Ascough S, Paterson S, Chiu C. Contrasting Influenza and Respiratory Syncytial Virus: Review of induction and subversion of human protective immunity. Front Immunol. 2018; 2(9): 323.

[12]Zahran WA, Amal FM, Ahmed AS, Ghada RE, Hassan SB. Comparison of reverse transcription-PCR and viral culture for detection of respiratory syncytial virus in young children: relation to epidemiological and clinical findings. EJMM. 2017; 26(2): 27-36.

[13]Al-Mola GA, Ragheb A, Abass IR. Human Metapneumovirus (hMPV) associated with respiratory infection in children hospitalized with acute lower respiratory tract infection in Hilla - Iraq, Int J Dis. 2013;1 (2): 020-023.

[14]Aziz TA. Detection of human metapneumovirus in hospitalized children with acute respiratory tract infections in Sulaimani province, Iraq. J Med Microb Diagn. 2015; 4:2.

[15]Alameedy FM. Detection of Nucleoprotein gene of Human Metapneumovirus and Chemokines and Histopathology study. Int J Pharm Tech Res. 2016; 9(11): 203-208.

[16]Al-Charrakh AH, Ghanim AA, Jalal ATA. Detection of human Metapneumovirus and respiratory Syncytial Virus associated with asthmatic patients using direct fluorescent assay and Real time - PCR. Wasit J Sci Med. 2016: 8 (4): 52- 65.

[17]Al-Mossawi MMK, Al- Hamadani AA, Al-Hilali AH. Molecular Investigation Of Human metapneumovirus and Respiratory syncytial virus in Children in Al-Amarah City, Ph.D. thesis, College of Medicine University of Al-Qadisiayah, Iraq.2016.

[18]Atyah NS, Hula YF, Faisal GA, Iman MA, Manal AA. Molecular detection of subfamily pneumovirinae among children with flu-like illness by using RT-PCR. Curr Res Microbiol Biotechnol. 2017; 5(5): 12391244.

[19]Moe N, Stenseng IH, Krokstad S, Christensen A, Skanke LH, Risnes KR, et $a l$., The burden of human metapneumovirus and respiratory syncytial virus infections in hospitalized norwegian children. J Infect Dis. 2017; 216(1): 110-116. 
Detection of Respiratory Syncytial Virus and Human Metapneumovirus in Children with Respiratory

Tract Infection by Use Real Time Polymerase Chain Reaction

[20] Fry AM, Chittaganpitch M, Baggett HC, Peret TC, Dare RK, Sawatwong P, et al., The burden of hospitalized lower respiratory tract infection due to respiratory syncytial virus in rural Thailand. PloS one. 2010; 5(11): e15098.

[21]Weinberg GA, Schnabel KC, Erdman DD, Prill MM, Iwane MK, Shelley LM, et al., Field evaluation of TaqMan Array Card (TAC) for the simultaneous detection of multiple respiratory viruses in children with acute respiratory infection. J Clin Virol. 2013; 57(3): 254-260.

[22]Khadadah M, Essa S, Higazi Z, Behbehani N, Al- Nakib W. Respiratory syncytial virus and human rhinovirus are the major causes of severe lower respiratory tract infections in Kuwait. J Med Virol. 2010; 82: 1462-1467.

[23]Parsania M, Behzad P, Mohammad HP, Sama H, Aref A, Alireza N. Detection of Human Metapneumovirus and Respiratory Syncytial Virus by Real-Time Polymerase Chain Reaction Among Hospitalized Young Children in Iran. Jundishapur J Microbiol. 2016; 9(3): e32974.

[24]Odisho SM, Al- Bana AS, Yaassen NY. Detection of Respiratory syncytial virus infection in a sample of infants in Iraq. Iraqi J Med Sci. 2009; 7 (4): 11-19.

[25]Zhang L, Wenkuan L, Donglan L, Dehui C, Weiping $\mathrm{T}$, Shuyan $\mathrm{Q}$, et al., Epidemiological and clinical features of human metapneumovirus in hospitalised paediatric patients with acute respiratory illness: a cross sectional study in Southern
China, from 2013 to 2016. BMJ. 2018; 8:e019308.

[26]Mohamed E, Mona S, Reiche J, Jacobsen S, Thabit AG, Badary MS, et al., Molecular analysis of human metapneumovirus detected in patients with lower respiratory tract infection in upper Egypt. Int J microbial. 2014; 2014:290793.

[27]Essa S, Owayed A, Altawalah H, Khadadah M, Behbehani N, Al-Nakib W. The prevalence of human bocavirus, human coronavirus-NL63, human metapneumovirus, human polyomavirus KI and WU in respiratory tract infections in Kuwait. Med. Princ Pract. 2015; 24:382-387. [28]Reiche J, Jacobsen S, Neubauer K, Hafemann S, Nitsche A, Milde J, et al., Human metapneumovirus: insights from a ten-year molecular and epidemiological analysis in Germany. PLoS ONE. 2014; 9:e88342.

[29]Feng L, Li Z, Zhao S, Nair H, Lai S, Xu $\mathrm{W}$, et al., Viral etiologies of hospitalized acute lower respiratory infection patients in China, 2009-2013. PLoS One. 2014; 9: e99419.

[30]Zhou J, Ying P, Xiao-you P, Han-chun $\mathrm{G}$, Ya-ping S, Le-yun $\mathrm{X}$, et al., Human bocavirus and human metapneumovirus in hospitalized children with lower respiratory tract illness in Changsha, China Influenza Other Respi Viruses. 2018; 12:279-286.

[31]Panayiotou C, Richter J, Koliou M, Kalogirou N, Georgiou E, Christodoulou C. Epidemiology of respiratory syncytial virus in children in Cyprus during three consecutive winter seasons (2010-2013): age 
Detection of Respiratory Syncytial Virus and Human Metapneumovirus in Children with Respiratory

Tract Infection by Use Real Time Polymerase Chain Reaction

distribution, seasonality and association between prevalent genotypes and disease severity. Epidemiol. Infect. 2014; 142(11):2406-11.

[32]Hassan DA, Shwan KR, John Z. A Single-Center Study of Viral Respiratory Tract Infections in Hospitalized Children From the Kurdistan Region of Iraq, Global Pediatric Health. 2018; 5: 1-8.

[33]Reina J, Ferres F, Mena A, Figuerola J, Alcoceba E. Clinical and epidemiological characteristics of respiratory infections caused by human metapneumovirus in pediatric patients. Enform Infect Microbiol Clin. 2008; 26: 72-76.

[34] Zou LR, Mo YL, Wu D, Fang L, Li H, Chen QX, et al., Investigation of human metapneumovirus in children with acute respiratory tract infections in Guangzhou areas. Zhonghua yu fang yi xue za zhi [Chinese journal of preventive medicine]. 2009; 43(4): 314-318.

[35]Chen X, Zhang ZY, Zhao Y, Liu EM, Zhao XD. Acute lower respiratory tract infections by human metapneumovirus in children in Southwest China: a 2-year study. Pediatr Pulmonol. 2010; 45: 824-831.

[36] Khalil SO, Enan KA, Ali YH, Salim B, Watt IME, Zardis M. Detection and Molecular Characterization of Respiratory Syncytial Virus (RSV) in Children with Respiratory Signs in Khartoum State, Sudan 2011-2012. Am J Infect Dis Microbiol. 2015; 3 (1): 6-13.

[37]Al-Shami JAJ, Al-Obaidi N. Review of wheezing in children in maternity and children teaching hospital in Al- Diwaniyah /
Iraq. Babylon Med J. 2009; 6 (3- 4): 477 483.

[38]Banerjee S, Sullender WM, Choudekar A, John C, Tyagi V, Fowler $\mathrm{K}$, et al., Detection and genetic diversity of human metapneumovirus in hospitalized children with acute respiratory infections in India. $\mathbf{J}$ Med Virol. 2011; 83(10):1799-1810. [39]Bosis S, Esposito S, Osterhaus AD, Tremolati E, Begliatti E, Tagliabue C, et al., Association between high nasopharyngeal viral load and disease severity in children with human metapneumovirus infection. $\mathrm{J}$ Clin Virol. 2008; 42(3): 286-290.

[40]Ji W, Wang Y, Chen Z, Shao X, Ji Z, Xu J. Human metapneumovirus in children with acute respiratory tract infections in Suzhou, China 2005-2006. Scand. J Infect Dis. 2009; 41(10): 735-744.

[41]Ali SA, John VW, Qingxia C, Sameer F, Assem S, Eshan A, et al., Human metapneumovirus in hospitalized children in Amman, Jordan. J.Med. Virol. 2010; 82: 1012-1016.

[42]Da Silva ER, Pitrez MC, Arruda E, Mattiello R, Sarria EE, de Paula FE, et al., Severe lower respiratory tract infection in infants and toddlers from a non-affluent population:viral etiology and co-detection as risk factors. BMC Infect Dis. 2013;13:41.

[43] Wu P, Dupont WD, Griffin MR, Carroll $\mathrm{KN}$, Mitchel EF, Gebretsadik $\mathrm{T}$, et al., Evidence of a causal role of winter virus infection during infancy in early children asthma. Am J Respir Crit Care Med. 2008; 178: $1123-129$. 